\title{
Root containerization for physiological studies of shrubs and trees on rangeland
}

\author{
R.J. ANSLEY, P.W. JACOBY, AND B.K. LAWRENCE
}

\begin{abstract}
The use of metal and plastic barriers to contain root systems of woody plants is presented as a method to study water relations and other physiological responses of field-grown shrubs. This method has permitted the study of plant dependence on lateral root systems and provides a convenient method to isolate plant roots in an equal volume of soil for replicated studies of large plants under field conditions.
\end{abstract}

Key Words: honey mesquite (Prosopis glandulosa), plant water relations, lateral root system, moisture stress

Studies which focus on water relations of individual, fully developed woody plants occurring in natural rangeland settings may have been complicated by root system heterogeneity among replicate experimental plants as well as interactions between root systems of experimental plants with those of neighboring plants. These impediments have resulted in studies often being made with immature or seedling plants grown in small root containers and often under artificial ambient conditions. Moreover, inferences regarding responses of individual plants are often made based on field studies conducted at the community level when, in fact, variation among individuals may be considerable.

The objective of this paper is to describe a technique termed "root containerization" (RC) which can be used to enhance understanding of water relations of woody plants on rangeland. RC can be used (1) as a treatment effect to measure dependence of trees and shrubs on their lateral root system, or (2) simply as a research tool to standardize soil volumes available to root systems of individual plants in replicated in situ physiological studies.

\section{Materials and Methods}

We employed 2 methods to containerize honey mesquite (Prosopis glandulosa Torr.) trees in north central Texas during 1985 and 1986. The first method involved use of a ditching machine. Because most equipment operators employ a straight-line style of ditching, we used a hexagon pattern for the container (Fig. 1). Each cut was made tangent to a $3.5-\mathrm{m}$ radius from tree center. Distance of the container wall from canopy center was approximately equal to canopy diameter. Cuts were limited to a depth of $1.5 \mathrm{~m}$ with the use of a ditcher.

A metal barrier was constructed from sheets of aluminum salvaged from a print shop. Individual sheets $(60 \times 90 \mathrm{~cm})$ were assembled into a continuous roll by overlapping and stapling sheets to wooden lath. Metal sheeting was inserted into the $15-\mathrm{cm}$ wide cut, and soil, which was deposited on both sides of the cut, was hand-filled back into the cut as soon as possible to preserve herbaceous cover (Fig. 2). As settling occurred, additional soil was required to fill the barrier cut during the first growing season. Soils at the study site contained 30 to $40 \%$ clay, so trench stability was maintained during installation of the root barrier.

A tractor-mounted backhoe was employed in 1986 as a second method to containerize mesquite. Cuts followed the hexagon design as shown in Figure 1; however, the backhoe increased depth and width of cut to $2.5 \mathrm{~m}$ and $60 \mathrm{~cm}$, respectively. Two rolls of

\footnotetext{
Authors are post-doctoral research associate, professor, and technician, Texas Agr. Exp. Sta. Box 1658, Vernon 76384.

Research was funded in part by: University Lands-Surface Interests, Univ. Texas System, Midland; E. Paul and Helen Buck Waggoner Foundation, Vernon, Texas; and was conducted on the W.T. Waggoner Estate, Vernon, Texas.

This article is being published as technical article TA-22533 from the Texas Agricultural Experiment Station.

Manuscript accepted 26 August 1987.
}

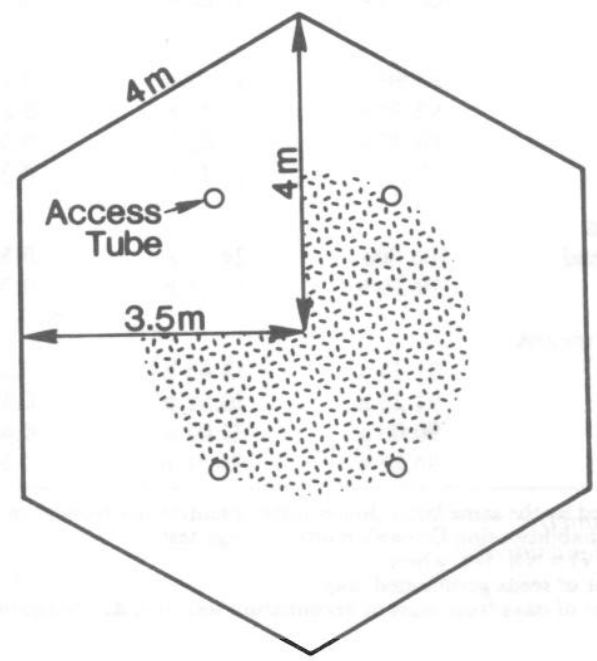

Fig. 1. Dimensions of hexagon-shaped root container and access tube location in relation to canopy (hatched area) of an experimental honey mesquite tree.

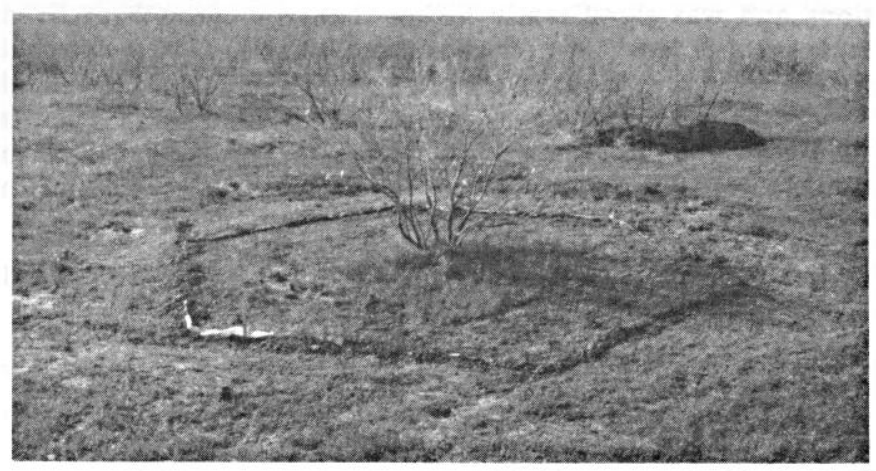

Fig. 2. Dormant honey mesquite tree with metal root barrier installed and ditcher trench refilled. Herbaceous community was preserved both inside and outside the root barrier.

aluminum sheeting were nailed in place to the interior wall (tree side) of the trench and a layer of 6-mil plastic was held in place around the metal barrier with 2 strands of 16-gauge wire. The trench soil, which was deposited outside the container, was then backfilled by crawler tractor.

\section{Discussion}

Both ditcher and backhoe were suitable for trenching prior to installation of root containers around honey mesquite trees. Primary advantages of the ditcher over the backhoe were less cost per tree and a narrower, more precise cut. A deeper cut was possible using a backhoe than a ditcher, effectively extending the sphere of 


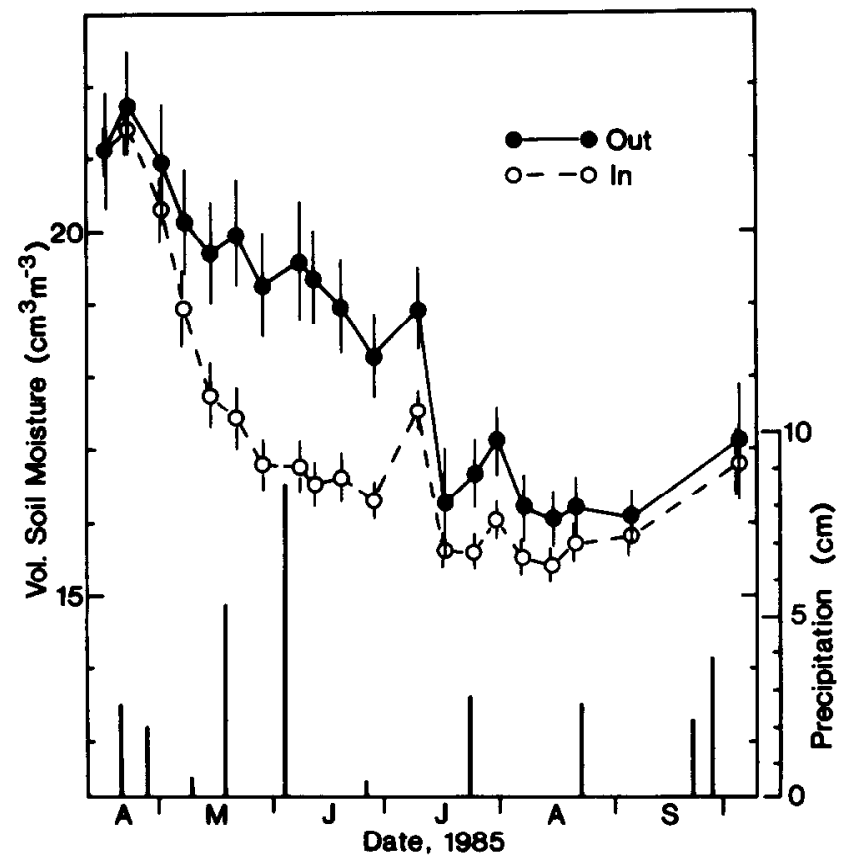

Fls. 3. Volumetric soil moisture content at $90 \mathrm{~cm}$ depth inside (mesquite + grass) and outside (grass alone) a mesquite root container, and precipitation during growing season, 1985 . Vertical bars $= \pm 1$ standard error; $r=8$. Soil moisture was measured using the neutron attenuation method (Greacen 1981).

influence of the container. Because the backhoe provided a trench wide enough for human access, it was possible to observe and quantify mesquite root density using inexpensive techniques.

Metal barriers were preferable to use of plastic alone because they were stronger, more durable, and remained in place instead of settling with the soil. It was less costly to install the metal barriers because a ditcher could be used rather than a backhoe. Because of the high heat conductance of metal, especially aluminum, differences in temperature regimes along the barrier interface were possible. We reduced this problem by trimming exposed portions of the barrier to within $1-2 \mathrm{~cm}$ above the soil surface.

Plastic not only was subject to puncture by cut roots during its installation, but to damage by burrowing animals. We anticipate plastic will erode over time and eventually its effect will be eliminated. We would not recommend the use of plastic alone for RC.

A combination of metal sheeting and plastic was preferable to either material alone. The metal protected the plastic from puncturing while the plastic provided an effective but temporary seal against lateral influx of soil moisture into the containerized area. The metal and plastic technique required use of a backhoe for trenching and thereby was more costly and time consuming to install than the other techniques.

Choice of technique depended on objectives of each study. We used RC in various capacities for 3 studies during 1985 and 1986, as outlined below. Following our studies we intended to excavate the barriers and observe their condition and root penetration, if any.

\section{RC as a Root Barrier Treatment}

Honey mesquite can develop deep tap roots, but depends primarily on extensive lateral roots for a majority of its water needs on upland range sites (Fisher et al. 1959, Ludwig 1977, Thomas and
Sosebee 1978). On certain sites where subsoil moisture is minimal or lacking, honey mesquite depends entirely on lateral roots to extract water. Roots have been found to extend $15 \mathrm{~m}$ laterally from velvet mesquite ( $P$. velutina) (Cable 1977). Information regarding dependence of honey mesquite on lateral roots was gained by measuring specific physiological parameters of containerized trees, and comparing these responses to adjacent trees which did not have $\mathbf{R C}$.

\section{RC as a Resenrch Tool}

In another study, information regarding patterns of water uptake activity by mesquite roots with respect to season and location within the soil profile was gained by using RC as a research tool. During installation of $\mathrm{RC}$ it was necessary to preserve the herbaceous community as much as possible both inside and outside the root barrier (Fig. 2). This allowed soil water extraction patterns of mesquite + grass inside the root container to be compared to that of grass alone outside the container. The ditcher was suited for this purpose because it provided a more precise, narrow cut than the backhoe. Labor required to refill the trench was also reduced because the ditcher removed less soil than the backhoe. Use of any method other than hand shoveling to refill the trenches with soil following insertion of the root barrier was impractical because of potential damage to herbaceous plants and surface soil horizon. Evidence that the barrier was effective in limiting water uptake by mesquite to the soil volume within the container is shown in Figure 3.

In a third study $\mathrm{RC}$ was again used as a research tool rather than treatment effect to aid in determination of how levels of moisture stress in honey mesquite affected response to subsequent moisture events. RC was used to control the rooting environment of individual trees for further manipulation to different levels of moisture stress using trickle irrigation and rain shelter techniques (Tanner 1967, Jacoby et al. 1988), and to remove competition from root systems of adjacent nonexperimental trees. Aerial dimensions (i.e., canopy volume and leaf area) of all experimental trees were similar. We assumed root/shoot ratios of all trees would likewise be similar, and standardizing soil volume available to each tree with RC would potentially reduce heterogeneity among replicates. Of course, standardization of soil volumes could actually increase variability among replicates if tree sizes were different. $R C$ would not affect other factors influencing variability such as soil type and genetic proclivity. A backhoe was better suited than a ditcher in this study for reasons already mentioned. Moreover, refilling the trench was done mechanically because scraping of herbaceous plants and soil surface outside the containers was not a concern.

\section{Literature Cited}

Cable, D.K. 1977. Seasonal use of soil water by mature velvet mesquite. J. Range Manage. 30:4-11.

Fiaher, C.E., C.H. Meadors, R. Behren, E.D. Robluson, P.T. Marion, and H.L. Morton. 1959. Control of mesquite on grazing lands. Texas Agr. Exp. Sta. Bull. 935, College Station.

Greacen, E.L. (Ed.). 1981. Soil water assessment by the neutron method. CSIRO, 314 Albert St., E. Melbourne, Victoria, Australia 3002.

Jacoby, P.W., R.J. Ansley, and B.K. Lawrence. 1988. Design of rain shelters for studying water relations of rangeland shrubs. J. Range Manage. 41:83-85.

Ludwis, J.A. 1977. Distributional adaptations of root systems in desert environments, p. 85-91. In: J.K. Marshall (ed.), The Belowground Ecosystem: A Synthesis of Plant Associated Processes. Range Sci. Dept., Colorado State Univ. Series No. 26, Fort Collins.

Thomas, G.W., and R.E. Sosebee. 1978. Water relations of honey mesquite-a facultative phreatophyte. Proc. 1st Int. Rangeland Congr., Soc. Range Manage., Denver, Colo. P. 414-418.

Tanner, C.B. 1967. Measurement of evapotranspiration. In: Irrigation of Agricultural Lands. Amer. Soc. Agron. 11:534-574. 